\title{
Sobre a generosidade: uma abordagem contemporânea da ética cartesiana
}

\author{
About Generosity: a Contemporary Approach \\ of Cartesian Ethics.
}

\section{*Érico Andrade M. de Oliveira}

\begin{abstract}
Resumo: O objetivo do meu artigo consiste em apresentar o conceito de generosidade como principal vetor para compreensão da moral cartesiana. Meu ponto éque esse conceito consegue, por um lado, articular diferentes paixões como humildade, amizade e amor numa mesma rede conceitual com o foco num projeto moral comum e, por outro, ele permite mostrar como Descartes articula num mesmo patamar razão e paixão para determinar a melhor forma de conduta humana. Com essa caracterização da generosidade acredito que é possível associar a ética cartesiana às preocupações da ética do cuidado, pelo menos, no sentido que a generosidade pode ser compreendida como uma disposição afetiva para a solicitude, para o cuidado.

Palavras-chaves: Cuidado. Descartes. Ética. Generosidade. Moral.

Abstract: In this paper I would like to present the concept of generosity as the main element for understanding the Cartesian moral. I think the concept of generosity can to articulate the different passions humility, friendship and love in the same conceptual network (in a moral philosophy). I think Descartes's project is to put on a same level reason and passion for determine the best form of human conduct. This characterization of generosity allows me to associate the Cartesian ethics of care. I believe, at least, the generosity can be understood as an affective disposition to care.
\end{abstract}

Keywords: Care. Descartes. Ethics. Generosity. Moral.

\footnotetext{
* Doutor em Filosofia pela Sorbonne (Paris IV). Professor adjunto da Universidade Federal de Pernambuco (UFPE). Coordenador do Grupo de trabalho da ANPOF: Estudos Cartesianos. <ericoandrade@hotmail.com>.
} 


\section{Introdução}

Tentar localizar no extenso leque das éticas contemporâneas o $\perp$ pensamento de um autor moderno não é uma tarefa fácil. Anacronismo é o primeiro risco. Risco, talvez, inevitável. Tenho consciência disso. Entretanto, parte do valor da fortuna crítica do filósofo está na leitura que renova seu pensamento em sintonia com questões que marcam o tempo presente. Nesse sentido, artigos e livros se multiplicam na tentativa de conciliar a posição cartesiana com algumas propostas morais recentes; notadamente com a ética das virtudes.

As várias passagens em que Descartes recorre ao conceito de virtude podem, aparentemente, abrir espaço para uma investigação que tenta traçar o elo cartesiano com a moral senão parcialmente aristotélica, pelo menos, próxima de algumas reflexões que caracterizam, em linhas gerais, a ética das virtudes de cunho aristotélico. Esse caminho de alguma forma guia as reflexões de autoras como L. Shapiro e Noan Naaman-Zauderer.

Não pretendo afirmar que essa aproximação é inviável, mas argumentarei em favor de uma aproximação que considero mais condizente com as preocupações cartesianas, a saber, com a ética do cuidado. Para isso, defenderei que a melhor maneira de caracterizar o próprio conceito de virtude é recorrendo ao conceito de generosidade que se remete no interior da obra cartesiana essencialmente ao cuidado dos outros, à solicitude. A minha hipótese, portanto, é que o conceito de generosidade governa a reflexão moral de Descartes cujo foco consiste na defesa do altruísmo como norte da ação moral. Penso que a virtude significa na filosofia moral cartesiana cuidado. Esse cuidado dos outros deve ser alimentado por uma educação moral que cultiva nas pessoas os sentimentos que protagonizam o cuidado do outro como principal intenção das ações humanas.

Para corroborar a minha hipótese, farei três discussões: 1) Mostrarei que o uso do conceito de virtude não é suficiente para recuperar, na moral cartesiana, indicações de que seu foco estava no estudo das virtudes; 2) Apresentarei brevemente as paixões como sentimentos, percepções ou emoções que não podem ser eliminadas por uma decisão da vontade. A vontade precisa atuar com as paixões para controlar as próprias paixões; 3) Farei uma investigação detalhada do conceito de generosidade para mostrar, por um lado, como ele revela a preocupação da ética cartesiana de centrar no cuidado dos outros o foco da ação moral e, por outro, para apresentar esse conceito como a chave que permite unificar reflexões cartesianas aparentemente pontuais sobre a moral, que se encontram disseminadas na análise de diferentes sentimentos morais, como amizade, amor e humildade. 
As vantagens da minha interpretação estruturam-se em dois pontos. Por um lado, porque tenta articular diferentes conceitos cartesianos relativos à moral que se encontram espalhados em diversos textos, sobretudo, da década de $1640^{1}$. Por outro lado, ela permite tecer alguns esclarecimentos quanto à relação entre razão e emoção na ética de modo geral por meio da ênfase na ideia de que o cuidado ou generosidade não é a antípoda de uma atitude racional, nem está restrito às fronteiras das relações familiares, mas que pressupõe uma ação conjunta da razão e das emoções e pode se estender para uma escala mais global. Meu objetivo é, portanto, apresentar o conceito de generosidade como o fio condutor que articula as diversas paixões humanas em função de um único projeto moral.

\section{Os limites do conceito de virtude para a compreensão da ética cartesiana}

O trabalho de Lisa Shapiro se coloca entre aqueles que procuram tecer uma leitura da moral cartesiana associada à preocupação de recuperar nela alguns traços da ética das virtudes. Seu objetivo expressamente não é reduzir a moral cartesiana à ética aristotélica (SHAPIRO, 2011, p. 442) que oferece as bases para a ética da virtude contemporânea, mas consiste em recuperar no controle das paixões, proposto por Descartes, indícios de que a virtude se estrutura em determinadas ações que privilegiam, de algum modo, a prudência. Para Shapiro, a posição cartesiana não é perfeitamente simétrica à ética da virtude; ela, de fato, guarda diferenças em relação à ética das virtudes, mas se coloca no mesmo quadro de referências dessa última na medida em que subordina o modelo de ação moral ao caráter virtuoso dessa ação expresso pela atitude que privilegia sempre a resolução de se manter firme em face das variações de conduta a que estão submetidas as ações movidas pela paixão.

A principal dificuldade para enquadrar a proposta moral cartesiana numa ética das virtudes é a ausência de referências sistemáticas de Descartes ao caráter do agente moral como marca importante para a construção de uma vida boa. De fato, o caráter do agente não é apresentado na filosofia cartesiana como uma importante variável para a construção de uma teoria moral. Entretanto, Lisa Shapiro argumenta que a

\footnotetext{
${ }^{1}$ Não tenciono discutir em que medida as reflexões realizadas a partir de 1640 consistem no desenvolvimento das máximas morais do Discurso do Método (sobre esse ponto ver, por exemplo, aqui no Brasil: OLIVA, 2008, e PINHEIRO, 1994). Independente de essas reflexões estarem ou não de acordo com as máximas da moral provisória ou por provisão (ver: SALLES, 2013), elas compõem, como veremos, uma reflexão moral bastante intensa e certamente mais ampla do que as máximas do Discurso.
} 
ênfase cartesiana na relação de subordinação da vida boa à ação virtuosa, presente em vários textos cartesianos, é um importante indicativo de que a sua preocupação incidia na tentativa de transformar as ações movidas pelas paixões em ações que expressam um exemplo virtuoso da procura pelo bem supremo. Nesse sentido, ela defende particularmente que um "rastreamento da segunda máxima (do Discurso)" pode mostrar a insistência cartesiana em caracterizar a virtude como o supremo bem (SHAPIRO, 2011, p. 441). Ainda que a ética cartesiana não seja uma continuação da ética aristotélica, menos ainda uma ética da virtude no estrito senso, ela guarda um compromisso especial com a virtude, inscrito na veiculação do bem à ação virtuosa.

Recentemente, outra interpretação tenta recuperar uma dimensão da moral cartesiana em sintonia com algumas temáticas que atravessam a ética contemporânea. Novamente a ética das virtudes está no foco da leitura da moral cartesiana. Entretanto, ela é balanceada com uma dimensão deontológica importante, que reconhece na obra de Descartes a preocupação em transformar a ação virtuosa num dever (NAAMANZAUDERER, 2010, p.179). Noa Naaman-Zauderer procura mostrar o caráter deontológico da moral cartesiana presente, segundo ela, na subordinação da ação correta do ponto de vista moral à correção do juízo moral endossado por ela. As crenças morais, quando legitimadas por bons argumentos, criam uma vinculação deontológica entre a norma e a conduta. Essa última deve se materializar na ação virtuosa. Ou seja, a virtude está subordinada ao bom uso da vontade livre. Só as ações que estão de acordo com esse critério podem ser consideradas ações virtuosas.

A vontade livre aproxima os seres humanos de Deus na medida em que indica o poder humano de se autodeterminar em consonância com o intelecto ${ }^{2}$. A unidade da vontade passa a coincidir com a unidade da sabedoria que determina na forma do dever o correto caminho a ser seguido para a felicidade. Por isso, argumenta Noa Naaman-Zauderer, Descartes caracteriza a virtude "em termos pragmáticos como o bom uso

\footnotetext{
2 Alexandre Soares defende que a sabedoria tem diferentes níveis no interior da obra cartesiana (SOARES, 2008. p. 274). Considerando que as crenças têm diferentes graus de certeza, crenças metafísicas são provadas por uma estrutura argumentativa cujo grau de exigência é radical, ao passo que outras crenças só podem ter, por assim dizer, um grau de clareza e distinção inferior ao grau das crenças metafísicas, é bastante razoável que a sabedoria esteja de acordo com a diversidade das crenças humanas. Gostaria de sublinhar apenas que isso não indica que não haja uma unidade da sabedoria que repousa, a meu ver, na unidade da razão (ver: ANDRADE, M. DE OLIVEIRA, 2006). Com efeito, mostrarei em outra oportunidade que as crenças morais estão de fato em outro nível de justificação em relação às crenças metafísicas. As crenças morais enquadram-se no estudo das questões, denominadas nas Regras, imperfeitas porque não são resolvidas apenas por uma análise do entendimento (Sobre esse ponto ver KAMBOUCHNER, 2008, p. 47-48).
} 
da vontade", visto que o que está em jogo é construir condições racionais para o exercício pleno e irrestrito da virtude (NAAMAN-ZAUDERER, 2010, p. 182). Assim, sem deixar de reconhecer que a moral cartesiana resiste a uma leitura consequencialista (NAAMAN-ZAUDERER, 2010, p. 184), Noa Naaman-Zauderer mostra que os últimos escritos de Descartes apontam para o caráter constitutivo do dever no que concerne ao uso livre da vontade. O juízo correto deve, portanto, indicar a melhor ação a ser realizada pela vontade (NAAMAN-ZAUDERER, 2010). Nessa perspectiva, Descartes estaria operando uma ética das virtudes que não se contenta apenas em sugerir (might) a prática da virtude, mas que exige ou obriga (ought) a prática da virtude.

Tenho dificuldade de seguir essas leituras que aproximam a moral cartesiana da ética das virtudes, por algumas razões que vou detalhar ao longo do artigo, mas gostaria de sublinhar desde já alguns argumentos que ponderam a possibilidade de compreender a moral cartesiana à luz da ética das virtudes. Primeiramente, não consigo vislumbrar uma preocupação realmente intensa de Descartes com o conceito de virtude. Longe de se mostrar intimamente ligada à tradição aristotélica, percebo que a obra de Descartes não discute detalhadamente o conceito de virtude que é usado apenas para expressar, de modo genérico, uma ação orientada pela razão. Nesse sentido, a virtude é sinônima da sabedoria que não se fragmenta em diferentes ações cuja classificação implicaria uma hierarquia, ou pelo menos, uma topografia das virtudes. Em outras palavras, a obra cartesiana não apresenta uma discussão sobre as diversas virtudes humanas que pudesse ser traduzida na forma de uma taxionomia das virtudes, própria, por exemplo, da filosofia aristotélica e de parte da filosofia medieval. Da identidade de uma ação boa com uma ação virtuosa não se segue que a ética cartesiana esteja na mesma esteira das éticas das virtudes. É preciso antes esclarecer o que Descartes entende por ação virtuosa.

Tenho plena consciência de que o conceito de virtude perpassa diferentes textos do corpus cartesiano. Meu ponto, contudo, é que as definições que Descartes oferece da virtude transitam sempre em torno de uma formulação abstrata que por si mesma não indica que ela esteja no mesmo compasso da ética das virtudes. A virtude é identificada à sabedoria, mas não a um conjunto mais ou menos extenso de diferentes virtudes. Aliás, num dos raros comentários mais prolongados sobre a virtude, a preocupação de Descartes em não proceder a uma taxionomia das virtudes é visível. Na carta à princesa Elisabeth, Descartes aproveita a oportunidade de comentar as regras morais do Discurso para declinar em relação à tarefa de fazer uma taxionomia das virtudes: 
A segunda, que mantenhamos a firme e constante resolução de executar tudo quanto a razão nos aconselhar, sem que nossas paixões ou nossos apetites nos desviem; e é a firmeza desta resolução que creio dever ser tomada pela virtude, embora eu não saiba de alguém mais que a tenha alguma vez explicado assim; mas dividiram-na em muitas espécies, a que foram dados diversos nomes, por causa dos diversos objetos aos quais se estende (Carta a Elisabeth, 4 de agosto de 1645/AT, IV, p. 265 - ver também a Elisabeth 18 de agosto de 1645).

Nessa resposta à rainha, Descartes demonstra seu desinteresse em dividir as virtudes - como analogamente ele está desinteressado, como mostram as Regras, em dividir o conhecimento como o fazem os filósofos em diferentes e, muitas vezes, incomunicáveis ciências (ver: ANDRADE M. OLIVEIRA, 2010) - e proceder por meio da análise de cada uma delas. É notável que a posição cartesiana consiste na unificação das virtudes na forma da sabedoria quanto ao exercício das paixões. A economia conceitual é uma regra metodológica crucial para Descartes (ver ANDRADE M. OLIVEIRA, 2010). Seu ideal ético não é a construção de uma teoria das virtudes que traça uma hierarquia das diferentes virtudes. Seu foco é na sabedoria requerida para a ação moral e sobre como ela pode operar no interior das paixões. Essa posição se aproxima da ética do cuidado que, descrente quanto à eficácia de uma teoria - taxionomia das virtudes - que poderia classificar as virtudes abstratamente por meio da correspondência biunívoca entre certas paixões e certas virtudes, propõe outro modelo moral cujo epicentro repousa nas emoções.

Numa das formulações possíveis da ética do cuidado, Noddings acentua que a sua diferença em face da ética das virtudes repousa num tratamento das emoções que não redunda numa teoria das virtudes: "Quando discutirmos o ideal ético, vamos começar falando sobre a virtude, mas não vamos deixar a virtude dissipar-se nas virtudes descritas em categorias abstratas" (NODDINGS, 2003, p. 107). Se, por um lado, Descartes reserva o termo virtude para designar a sabedoria prática de como lidar com as paixões, ele, por outro, se posiciona contrário à investigação das virtudes por meio de uma análise das diferentes virtudes ou das diferentes ações virtuosas que poderiam categorizar as virtudes numa estrutura hierárquica. Ele e Noddgins parecem estar de acordo quanto aos limites de uma ética centrada nas virtudes.

Descartes sempre se mostra resistente quanto à tarefa de promover uma teoria das virtudes que procura estabelecer para cada comportamento humano uma ação virtuosa correspondente. Esse era o epicentro da crítica que ele reservava aos estóicos que desrespeitavam a prerrogativa central do método de ensinar o modo de conduzir corretamente as ações. Nas linhas que encerram as suas primeiras reflexões publicadas sobre a moral, 
ele não se furta a pontuar que a sua discordância em relação aos estóicos reside na ausência de uma precisão, por parte daqueles filósofos, sobre o que significa agir de modo virtuoso: "[eles] elevam muito as virtudes e fazem-nas parecer muito mais estimáveis do que qualquer outra coisa, mas não ensinam suficientemente a conhecê-las" (AT, VI, p. 7-8). Meu ponto é que esse comentário só pode ser plenamente compreendido caso se considere o projeto metodológico cartesiano de colocar em evidência a maneira pela qual as coisas são descobertas ${ }^{3}$.

Nesse sentido, a ética cartesiana conserva uma preocupação metodológica, pelo menos, no sentido de subordinar a virtude ao ensino do modo pelo qual ela pode ser praticada. É preciso mostrar como a sabedoria prática ou a virtude opera na orientação da conduta humana e não fazer uma classificação abstrata das diferentes virtudes humanas que esconde essa orientação. Cumpre entender como se dá a prática da virtude, pois é na prática da virtude e não no estudo da virtude que se concentra a moral cartesiana. Uma interpretação que procura mapear as virtudes, supostamente defendidas como modelo de ação na moral cartesiana, não encontra muito sucesso porque a virtude não se fragmenta em diversos níveis de atuação, mas encerra um modo geral por meio do qual Descartes se refere ao controle das paixões. Como esse controle de fato ocorre pode ser mais bem entendido se investigarmos o motivo pelo qual ele é desejado e a estratégia graças a qual ele pode ser atingido.

\section{A inescrutabilidade das paixões}

É notável ainda que o recurso à ética das virtudes pressupõe um ponto com o qual estou de acordo porque guarda uma forte ligação com a ética do cuidado. Uma marca importante dos autores contemporâneos que advogam em favor de uma ética das virtudes consiste numa crítica, por vezes, contumaz à ética racionalista, entendida como uma posição que aposta em instâncias neutras (procedimentais ou contrafactuais) de validação das crenças morais. Embora Descartes não se detenha a uma crítica pormenorizada da ética racionalista, ele se mostra reticente a uma proposta moral governada por imperativos a priori e estritamente racionais ou ainda sem nenhuma vinculação com as emoções. Acredito que o motivo dessa resistência é a onipresença das paixões humanas na

\footnotetext{
${ }^{3}$ A preocupação com o caráter prático do conhecimento foi o que impulsionou Descartes à procura incansável por um método seguro. Para Descartes, o método consiste mais em prática do que em teoria (AT, I, 349), porque é essencial ensinar por meio da própria atividade investigativa a maneira correta de conhecer, para que todos possam se orientar numa determinada investigação.
} 
conduta dos agentes morais expressa por Descartes, de modo lapidar, na seguinte passagem: "parece-me que podemos defini-las [as paixões] em geral por percepções, sentimentos ou emoções da alma que referimos particularmente a ela, e que são causadas, mantidas e fortalecidas por algum movimento dos espíritos" (TP, art. 27/AT, XI, p. 249). Ou seja, as paixões não dependem apenas da alma, mas também da estrutura do organismo humano cujo funcionamento é constante e nos acompanha durante a nossa existência integralmente. Argumentarei agora em favor da tese de que as paixões estão presentes integralmente em nossas ações e que elas não podem ser controladas diretamente pela vontade o que não significa dizer que elas são incontroláveis.

Descartes guarda a convicção de que, embora a vontade humana seja completamente livre, ela não tem o poder de neutralizar as paixões diretamente, por meio de uma resolução da razão. A vontade não pode controlar o corpo completa e irrestritamente. Além das funções vitais do corpo, que são autônomas, não controlamos as sinapses elétricas de nosso cérebro, nem a circulação dos espíritos animais que mantém o nosso corpo em atividade constantemente. É importante notar que a ligação da alma com o corpo tem uma via dupla para Descartes, pois um influencia o outro. As paixões desencadeadas pelo corpo não podem ser simplesmente suplantadas por uma deliberação da vontade, e não há remédio capaz de estancar os efeitos sentidos no corpo por conta de uma emoção como, por exemplo, a tristeza que acomete a alma conforme relato de Descartes a princesa Elisabeth (Carta a Elisabeth, maio ou junho de 1645 - AT, IV, p. 220).

Não pretendo discutir nesse momento como ocorre a relação da alma com o corpo (escreverei um artigo para tratar apenas sobre esse ponto). Gostaria de sublinhar que essa relação impede que a vontade possa atuar simplesmente como se o ser humano não tivesse corpo o qual é muitas vezes responsável por desencadear e manter viva uma paixão. Essa é a tônica que rege umas passagens mais claras do Tratado das Paixões em que Descartes expressa os limites da vontade humana no que concerne à sua atuação sobre as paixões ${ }^{4}$. A vontade não pode eliminar as paixões:

\footnotetext{
${ }^{4}$ Não pretendo pôr em dúvida a importância da medicina para o pensamento cartesiano, mas não estou convencido de que a moral cartesiana seja um capítulo da física ou que ela pudesse ser vista como uma antecipação de uma posição naturalista em termos de ética como sustentam alguns intérpretes (por exemplo: FORLIN, 2011, p. 164) e como Descartes sugere na seguinte passagem: "meu intuito não foi explicar as paixões como um orador, nem como um filósofo moral, mas somente como um físico" (TP/AT, XI, p. 326). Acredito que o uso do termo física para denotar o modo pelo qual Descartes tenciona investigar as paixões envolve um posicionamento negativo em face da possibilidade de tratar a moral desvinculada da condição humana para qual o corpo é tão importante quanto a alma. Tratar as paixões como um físico é compreender o comportamento humano em função dele mesmo, sem recorrer, portanto, a nenhum subterfúgio metafísico, amparado numa investigação estrita da alma. Reconhecer
} 
"Nossas paixões também não podem ser diretamente excitadas nem suprimidas pela ação de nossa vontade, mas podem sê-lo, indiretamente, pela representação das coisas que costumam estar unidas às paixões que queremos ter, e que são contrárias às que queremos rejeitar" (TP, art. 45/AT, XI, p. 362-363). Não é facultado à vontade humana o poder de viver sem as paixões enquanto ela estiver, por assim dizer, encarnada no corpo. Isso não significa que a vontade não possa controlar as paixões, mas aponta para a ideia de que não é possível pensar o ser humano sem considerar as paixões. A vontade não pode decidir por não se submeter a uma paixão. Um ser sem as paixões seria uma máquina, um autômato como os animais, na melhor das hipóteses um anjo, mas certamente não seria um ser humano 5 .

O desafio que se impõe à filosofia moral não pode consistir, portanto, em outra coisa senão conviver com as paixões. O primeiro passo em direção à filosofia moral é saber os limites da vontade. Esse passo tem um caráter prático, porque envolve os limites de atuação da vontade humana no nosso comportamento, na mesma medida que requer uma atividade do entendimento de definir os limites de atuação da vontade. A epistemologia se une à moral para traçar as fronteiras de atuação da vontade. O entendimento nesse ponto específico se mantém protagonista na filosofia cartesiana, pois ele é responsável por delimitar o campo de atuação correto da vontade.

É importante lembrar que um dos pontos centrais da epistemologia cartesiana, discutido por mim em outras oportunidades, consiste em oferecer mecanismos conceituais que podem traçar limites do que é necessário para tornar uma crença razoavelmente certa. Do ponto de vista moral, a certeza está ligada à prática ou ao exercício do ser humano de agir corretamente. Assim, a demarcação desenhada no Tratado das Paixões deve indicar os limites de atuação da vontade no que concerne àquilo que ela pode interferir certamente nas paixões e determinar, na medida do possível, a conduta humana. Ou seja, Descartes se esforça

que o corpo humano é um importante vetor para afastar a moral do âmbito do formalismo ou da pura especulação, cujo poder de persuasão varia de acordo com a força retórica do discurso dos oradores. É preciso tecer uma moral em sintonia com as nossas disposições orgânicas, mas não reduzidas a ela.

5 Deus, por não ter corpo, não pode ter paixões. Os animais, por não terem alma, não podem ter paixões. Apenas os seres humanos, que têm corpo e alma, podem ter paixões. Essa condição torna singular a existência humana. Em relação aos animais, a tese cartesiana de que eles não sentem foi matizada por ele quando afirma que a "mente humana não atingiu seus corações" no que concerne à prova de que eles não sentem (Carta a Huygens (?) 5/02/1649 - AT, V, p. 277) o que levou alguns intérpretes como Cottingham a colocarem algumas dúvidas sobre a completa falta de sentimentos dos animais. Em outras cartas ele pondera a possibilidade de os animais sentirem, mas, em geral, como mostra Ethel Rocha (2004), Descartes mantém a posição de que eles, de fato, não possuem paixões. 
para demarcar o campo de atuação da vontade para que ela não se perca no caminho absolutamente improfícuo de tentar suprimir as paixões como se a alma, enquanto estamos vivos, pudesse atuar no terreno das paixões sem o corpo. A via que o método traça para a filosofia moral se inicia pelo disciplinamento da vontade para não desejar o que não pode realizar. Ela não pode desejar que a alma não tenha paixões. Se do ponto de vista epistêmico a vontade, quando opera sem a garantia epistêmica do entendimento referente à clareza e distinção de uma crença pode enredar em erros, do ponto de vista moral, ela pode realizar ações que se distanciam do que pode ser ulteriormente tomado como bom quando ela tenta operar sem levar em consideração as paixões e as suas respectivas intenções que podem conduzir os seres humanos a "conservarem a sua vida". Não está em jogo exigir da vontade o que ela não pode fazer. A alma humana não pode pretender "estancar rapidamente as suas paixões" (TP, art. 46/AT, XI, p. 363-364), pois isso é incompatível com a própria condição humana. A antropologia cartesiana torna inviável a eliminação das paixões. O controle que a vontade pode exercer sobre as paixões deve ser, portanto, de outra natureza.

A passagem supracitada traz algumas indicações de como esse controle das paixões pode ser exercido pela vontade. É notável que Descartes abre a possibilidade de intervenção da vontade nas paixões. Essa intervenção é, contudo, indireta, como disse. Ou seja, a vontade não pode atuar nas paixões apenas por um processo de apresentação de objetos alternativos em relação aos que despertaram certa paixão. Embora o interesse por certo objeto possa perdurar, ele pode ser canalizado - e nesse sentido sublimado - pela apresentação de outro objeto. Esse objeto pode ser um desejo cuja realização requer uma determinação da vontade em longo prazo que tenta controlar as paixões para que esse desejo, que é uma paixão, seja realizado, bem como pode ser a apresentação de pessoas ou interesses que despertem outras paixões para equilibrar as diferentes paixões. É importante notar aqui que a vontade não age sobre a paixão diretamente. Ela apenas representa, para si mesma, outros caminhos que podem despertar outras paixões ou que podem moderar (temperar) uma paixão existente.

À razão é facultada a possibilidade de planificar as paixões por meio da introdução de objetos que despertam o interesse humano. Ela não pode dissuadir diretamente o ser humano do que ele sente. Todavia, ainda que as nossas ações sejam movidas por uma paixão, é possível agir em conformidade com os conselhos da razão (Carta a Elisabeth, 4/08/1645 - AT, IV, 1645), mas é necessário reconhecer que, como aponta muito bem Renault, esse movimento da vontade "revèle toujours de l' appétit sensitif" (RENAULT, 2000, p. 192), e não opera sem a mediação 
das paixões. No movimento que a vontade realiza no horizonte da atuação humana, não faz sentido colocar em espectros antagônicos paixão e razão. Não há a priori conflito entre razão e sensibilidade, transcrito por um conflito entre um sujeito racional abstrato e um sujeito empírico, sensível. No interior da vontade humana é possível resgatar uma boa vontade quando ela sabe orientar as paixões humanas em sintonia com os conselhos da razão. As paixões não retiram do ser humano o poder da razão de orientar o caminho em busca de uma vida boa. Pelo contrário, as paixões podem contribuir para uma vida boa quando aquilo que elas intencionam é dosado na medida certa de acordo com um plano instituído em longo prazo, para o qual a participação da razão é muito importante. A razão pode fornecer a prescrição precisa do remédio, bem como a sua medida, mas nunca pode atuar sem a mediação das paixões.

Nesse caso, a sabedoria reside na procura por uma forma de controle das paixões que não tenha a pretensão de eliminá-las por uma decisão da vontade, tomada a partir de uma reflexão estritamente racional. Um projeto moral que desconsidera esse limite da vontade tomaria o falso por verdadeiro e infringiria uma regra fundamental do método cartesiano. A onipresença das paixões, contudo, não significa que estamos submetidos ao ritmo natural e acidental que elas podem ocorrer no ser humano. É perfeitamente possível fazer as paixões atuarem em nosso favor. A moral desempenha na filosofia cartesiana justamente o papel de controlar as paixões para que elas possam nos servir ao invés de nos aprisionar, pelo menos é isso que se pode atestar no artigo 144 do Tratado das Paixões: "Mas, dado que essas paixões não podem levar a nenhuma ação, exceto por intermédio do desejo que excitam, é particularmente esse desejo que devemos ter o cuidado de controlar; e é nisso que consiste a principal utilidade da moralidade" (TP art. 144 Descartes).

É notável que Descartes não alimenta a tese de que a moral é um terreno insondável para a razão, mas ele se recusa a endossar uma tese oposta, conforme a qual a autodeterminação da vontade poderia acontecer independente das paixões ou ser indiferente a elas. O controle das paixões não enquadra a paixão e a razão em dois planos antagônicos. O desafio é conciliar a razão e as paixões. Entretanto, o modo como Descartes propõe essa conciliação é que transcreve a sua posição inovadora. Ele irá conciliar razão e paixão recorrendo paradoxalmente a uma paixão que é capaz de se converter em virtude, a saber, a generosidade. Acredito que o recurso ao conceito de generosidade é a melhor forma para compreender a moral cartesiana e esclarecer o próprio uso do conceito de virtude, porque esse conceito mostra como a moral, para Descartes, não põe em dois planos distintos a razão e as paixões (emoções) quando faz de uma paixão o espelho da conduta correta. 


\section{Generosidade como cuidado}

"Quod vitae secatabor iter?"

(DESCARTES)

Vou testar mais diretamente a minha hipótese de que a ética cartesiana compreende a generosidade como o cuidado com os outros que deve resultar, tomando emprestadas as palavras de Dall'Agnol, "em ações que beneficiem aquele que é cuidado pelo bem dele mesmo" (DALL'AGNOL, 2010 , p. 30). Ou seja, penso que a ética cartesiana é orientada pela determinação que confere a conduta humana o predicado moral quando ela se associa a uma disposição afetiva e genuína de solicitude para com os outros. Se estiver certo, é possível aproximar, em linhas gerais, a ética cartesiana da ética do cuidado.

É importante destacar inicialmente que a procura por uma taxionomia das paixões marca parte da reflexão da escolástica tardia e se dissemina nos primeiros raios da modernidade. Dilatava-se pelos corredores das abadias e pelas primeiras salas das universidades a tentativa de oferecer a melhor imagem do conjunto das paixões humanas. Era possível encontrar, antes da publicação do Tratado das Paixões, uma série de reflexões sobre a moral que se avolumavam em torno da procura da melhor classificação e divisão das paixões. Por conseguinte, a originalidade da reflexão cartesiana sobre as paixões não repousa tanto na divisão proposta no Tradado das Paixões, nem no eventual refinamento das definições de cada paixão. Acredito que o ponto é a defesa da generosidade - pouco conhecida, segundo Descartes, entre os escolásticos (TP, art. 161/AT, IX, p. 453-454) - como um misto de virtude e paixão cuja principal característica é a orientação da ação humana em direção ao cuidado com os outros à proporção que retira os seres humanos da procura apenas pelos seus interesses individuais e imediatamente tangíveis.

Se a generosidade consiste, em linhas gerais, no bom uso da vontade (TP, art. 153/AT, IX, p. 445-446), ela se materializa na conduta humana que fortalece o cuidado com os outros como meta da ação. A formulação mais geral da generosidade que a define como uma firme e constante resolução de bem usar a vontade (definição que, aliás, mostra a simetria dos conceitos de virtude e generosidade TP, art. 153/AT, IX, p. 445-446) é incorporada na prática humana como a disposição de reconhecer no cuidado com os outros a melhor forma de limitar a vontade à procura por fazer aquilo que de fato lhe conduz à felicidade e sobre o qual temos controle. Nessa perspectiva, as propriedades da generosidade reputam o cuidado como a ação mais promissora para o equilíbrio das paixões. $O$ principal remédio para dosar as paixões é o cuidado que consiste apenas 
no cultivo das ações que contribuem para que os outros sejam assistidos enquanto outros. Assim, quando Descartes oferece uma descrição dos que são generosos, ele não se furta em introduzir o cuidado como uma marca constituinte da generosidade:

Os que são generosos dessa forma são naturalmente levados a fazer grandes coisas, e, todavia, a nada empreender de que não se sintam capazes; e, como nada estimam mais do que fazer bens aos outros homens e desprezar o seu próprio interesse, por esse motivo são sempre perfeitamente corteses, afáveis e prestativos para com todos. E com isso são inteiramente senhores de suas paixões (TP, art. 156/AT, XI, p. 469-470).

O que aqui parece paradoxal, a saber, o recurso a uma paixão para o próprio controle das paixões, é uma novidade que a moral cartesiana introduz na história da filosofia. Ressoa nessa passagem a convicção de que a prática do bem tem, por assim dizer, uma intencionalidade cuja raiz está num sentimento que, quando praticado, se transforma numa virtude moral. Esse sentimento dirige as ações humanas em direção ao cuidado com seres humanos para desviar o interesse imediato de se orientar pelo desejo do agrado fácil de um prazer passageiro, efêmero. Assim, a estima por si mesmo não deve conduzir os seres humanos a reconhecerem a legitimidade apenas do que se lhe oferta como a imagem do seu próprio interesse.

Por outro lado, a generosidade cultiva a capacidade, como pontua Laurence Renault, no interior da discussão sobre os sentimentos morais, de "considerar o outro como o nosso igual" (RENAULT, 2011, p. 72), porque ela apresenta o ser humano como igual não apenas na constituição de suas faculdades, mas também na estrutura de suas falhas. Um passo decisivo para o reconhecimento da necessidade do método foi o reconhecimento de que o erro de tomar crenças falsas como verdadeiras não é um desvio acidental do conhecimento humano, mas é muito comum quando se procede sem predeterminar a ordem das dificuldades da investigação. A ética cartesiana enreda no mesmo raciocínio: um passo decisivo para o fortalecimento das crenças morais é reconhecer que os desvios de conduta não são acidentais, mas são comuns quando se desconsidera o outro como igual, ou mais gravemente, como aquele que inspira cuidados.

Parte dos excessos que o projeto moral cartesiano quer combater está no peso que os indivíduos atribuem para si mesmos quando deixam de se pautarem no comportamento generoso. Nesse sentido, o horizonte em que se movem os indivíduos que se refugiam nos limites do seu eu é o da estima de si ou, como afirma Descartes, "Todos os que concebem boa 
opinião de si próprios por alguma outra causa, qualquer que seja, não têm verdadeira generosidade, mas somente orgulho que é sempre muito vicioso..." (TP, art. 157/AT, XI, p. 448-449). As pessoas orgulhosas tendem a se valorizar por bens que, embora em alguns casos sejam importantes, de modo contingente, para a vida, os diferencia dos outros, tais como "a beleza, as riquezas, as honras etc." (TP, art. 158/AT, XI, p. 449). Para eles, a perda desses bens pode os levar a cultivarem paixões, nesse contexto, absolutamente indesejáveis, como "ódio, inveja, ciúme e cólera" (TP, art. 158/AT, XI, p. 449).

A generosidade é uma forma de evitar que o cultivo da boa opinião de si próprio (TP, art. 157/AT, XI, p. 448-449) ofusque os seres humanos e lhes conduza a cristalizar uma imagem inquebrável de si mesmo. Essa imagem de si, distorcida pela ambição, cultiva nos indivíduos o sentimento de que as suas ações são dignas de louvor independente de conseguirem transpassar as fronteiras do seu próprio ego. Elas podem aprisionar as pessoas nas fronteiras do seu ego, tornando-as incapazes de qualquer forma de aperfeiçoamento moral, ao passo que a generosidade dissolve o orgulho e, com ele, os excessos que o acompanham, quando mostra que o maior bem e o único que podemos controlar de modo satisfatório é o cuidado com os outros. Isto é, a generosidade nos permite um controle das paixões porque ela apresenta uma forma de comportamento que não é acidental, porque todos nós precisamos, pelo menos em algum momento de nossas vidas, de sermos assistidos por alguém, e que depende inteiramente de nós o cuidado do outro. Quando resolve cuidar do outro, o ser humano consegue se desviar dos interesses próprios e das paixões que sempre acompanham aquele interesse de modo desmedido, desregrado. É nesse sentido que os seres humanos se tornam senhores de suas paixões e, "particularmente dos desejos, do ciúme e da inveja" (TP, art. 156/AT, XI, p. 447-448). O excesso das paixões é diretamente proporcional ao apego aos próprios interesses. Se os que são cuidadores (os generosos em termos cartesianos) não devem agir em função dos eventuais elogios (NODDINGS, 2002, p. 40-41), é porque devem priorizar a proteção do outro que implica um desapego em relação aos interesses que não se configuram numa relação genuína de cuidado, de proteção do outro.

Diante de bens transitórios e efêmeros, cujo sabor pode variar de acordo com a instabilidade das paixões, a filosofia moral cartesiana lança mão de um único bem que deve governar a conduta humana e certamente não nos deixará expostos ao sabor das contingências, a saber, a conduta generosa que cultiva o cuidado dos outros. Numa espécie de dissolução do hiato de tempo que separa a redação do Tratado das Paixões e as correspondências que lhe antecedem, Descartes mostra que a sua reflexão 
perpassa, em diferentes momentos, a mesma convicção de que o centro da moralidade está no cuidado que se converte no maior bem moral, pois não se estima "nada maior do que fazer bem aos outros homens" (TP, art. 156/AT, XI, p. 447-448). Ou, como ele afirma na correspondência com Elisabeth, "Ademais, além disso, como é uma coisa muito mais alta e gloriosa de fazer o bem aos outros homens do que procurar fazê-lo para si mesmo..." (Carta a Elisabeth, 06 de outubro de 1645 - AT, IV, p. 317). A defesa do altruísmo situa a filosofia moral cartesiana no horizonte de uma ética que esvazia o componente moral de todas as ações cujos interesses não conseguem ultrapassar as fronteiras do si mesmo. Numa das formulações de Nodding, a ética do cuidado, a assistência ao outro deve ser feita sem a prerrogativa de subtração de dividendos: "Não agimos para conseguir um elogio a nós mesmos, mas para proteger ou melhorar o bem-estar do objeto do cuidado" (NODDINGS, 2002, p. 40-41). A posição cartesiana parece estar de pleno acordo porque a ação generosa não dever esperar nada em troca.

Por conseguinte, a generosidade é introduzida na moral cartesiana para combater o egoísmo que Descartes julga ser uma das principais fontes de excesso e, por conseguinte, de descontrole das paixões. Nesses termos, no centro da moral cartesiana está a recomendação da generosidade como um antídoto contra o desregramento das paixões, porque ela pode converter a ambição, que subordina a ação egoísta do indivíduo à recompensa de sua ação na forma de dividendos financeiros ou de outra natureza, em humildade, conforme a qual é possível se desviar de excessos como a inveja e o ódio por meio da consciência de que a nossa ação deve ser compatível com que podemos realizar. Ou seja, o altruísmo na forma da generosidade é introduzido na esperança de dissuadir os seres humanos de condicionarem as suas ações à procura pelo benefício próprio.

Para evitar que nosso comportamento se transforme numa prisão cercada de espelhos, é importante cultivar a humildade não como uma submissão voluntária às nossas faltas e aos nossos defeitos, mas como uma maneira de reconhecer que o erro é a marca da nossa condição. Nesse sentido, a humildade pode, de algum modo, alimentar a simpatia no sentido de que o reconhecimento de que falhamos pode cultivar uma maior solicitude para aqueles que cometem falhas. Nesse ânimo, Descartes descreve os que são generosos como aqueles que são capazes de migrar da ilusão da infalibilidade para a compreensão dos limites da condição humana e dos limites dos outros:

Assim, os mais generosos costumam ser os mais humildes; e a humildade virtuosa consiste apenas em que a reflexão que fazemos 
sobre a debilidade de nossa natureza e sobre as faltas que podemos ter cometido outrora, ou somos capazes de cometer agora, não são menores do que as que podem ser cometidas por outros [...] [TP, art. 155/AT, XI, p. 447].

A humildade promove a simetria entre os seres humanos quando os faz experimentar não uma diferença, por assim dizer, de talentos, mas uma igualdade de vulnerabilidade às falhas próprias de uma condição inacabada que atravessa o conturbado mar das paixões como a dificuldade de um marinheiro cuja visão se embaça quando não se projeta, por meio de um instrumento fabricado pela razão, para além dos limites do seu próprio barco.

Para evitar se perder no mar em que a maré está fortuitamente descontrolada por um turbilhão de diferentes paixões, o sujeito moral não pode contar, permitam-me a expressão, com a sorte moral. É preciso alimentar a generosidade para que "as mudança de humor e adversidade" (TP, art. 159/AT, XI, p. 450) não nos escravizem e nos mantenham dependentes do que não podemos controlar. Por isso, o cultivo da generosidade deve ser constante, como são constantes, aliás, as paixões. Para voltar à imagem do marinheiro é necessário que se regule os humores pela firme resolução de ser generoso, para que os revezes da viagem sejam convertidos num aprendizado graças ao qual saberemos controlar as sensações e torná-las subordinadas à nossa vontade. Os generosos, conclui Descartes no mesmo artigo, "não mudam de humor nas prosperidades ou adversidades que lhes ocorrem" (TP, art. 159/AT, XI, p. 450), pois no lugar de se enclausurarem nos contornos do próprio ego, os que praticam a generosidade devem "ter boa vontade para com todos" (TP, art. 187/AT, XI, p. 470), por reconhecerem que ninguém está livre de cometer falhas, e devem ter temperança no modo de lidar com os erros alheios. Nutrir a cólera e a inveja muitas vezes é uma forma velada de se colocar no registro do infalível. Concedendo que todas as pessoas são vulneráveis à falha, é possível controlar, por meio da humildade, sentimentos como cólera e ira para evitar que eles se transformem em formas mais fortes de violência e desequilíbrio emocional.

Assim, a generosidade é tão radical que ela exige dos indivíduos um desprendimento de si mesmo ou um arrefecimento do seu orgulho. Por meio do recurso à generosidade o agente moral não confere tanta força aos insultos que lhe são impingidos quanto confere à capacidade de perdoar. Não está no nosso horizonte de atuação o controle das ações dos indivíduos que nos ofendem, mas a nossa reação à ofensa pode ser controlada quando se reconhece na falha do comportamento agressivo um agente que, por um lado, pode não ter agido de má fé ou má vontade 
e que, por outro, comete um erro no qual todos nós podemos eventualmente incorrer.

Acredito que o conceito de generosidade governa a realização daquilo que Descartes chama, nas passagens supracitadas, fazer bem aos outros homens. Primeiro, é preciso dissuadir qualquer pretensão de racionalização do fazer bem que poderia orientar a moral cartesiana em direção a uma teoria cujo ponto central seria a procura pela realização do bem da maioria. O fazer bem aos outros não assume, em nenhum momento da filosofia moral cartesiana, a forma de uma teoria que afere os resultados da conduta pela extensão dos beneficiados por uma determinada ação. O bem não é a expressão de uma imagem monótona dos sentimentos morais que cristaliza o prazer ou o não sofrimento como o padrão de medida da ação. Não se trata de distribuir para os seres humanos a mesma medida de um mesmo sentimento de prazer como a imagem de uma paixão petrificada num modelo monolítico de atuação moral. Essa posição é tanto rejeitada quanto indesejada por Descartes. É indesejada porque, embora o bem seja governado por uma paixão, a generosidade, ele não cristaliza nenhuma paixão como a representação unilateral da vontade humana, pois, as várias paixões, desde que guiadas pela generosidade, podem contribuir para a felicidade. Essa posição é rejeitada também porque as paixões não são a priori boas ou más (Carta a Chanut, 01/11/1646 - AT, IV, p. 538; ver também: TP, art. 157/AT, IX, p. 448-449), mas podem receber predicados morais de acordo com o uso que fazemos dela. Ou seja, ter ou não ter prazer não torna em si mesma uma ação mais ou menos moral. Ela é igualmente indesejada porque a aposta cartesiana não é na instituição de uma paixão em detrimento das outras, mas numa paixão que administre (ou que exerça uma técnica de controle, como dizia Lívio Teixeira, 1986) as outras por meio da ênfase no que cada paixão pode contribuir num dado contexto para a realização da vida feliz.

Nessa perspectiva, fazer bem aos outros é modelar as ações em função de um sentimento que não se ramifica num único desejo dos seres humanos, por mais simples e intuitivo que possa parecer esse desejo. Essa proposição cartesiana aponta para o altruísmo como foco da filosofia moral, mas não se remete a um altruísmo que, sob a desculpa de fazer bem aos outros, estende o egoísmo a uma escala social (sobre a crítica à posição utilitária em moral ver: ANDRADE M. OLIVEIRA, 2013). O bem para si mesmo é a consequência e não a causa da ação. Só aqueles que conseguem genuinamente se ocupar de cuidar dos outros é que podem se desviar de paixões que nos amarram aos grilhões da vaidade ou do orgulho de si mesmo. O cuidado deve ser incondicional, semelhante, como afirma Descartes, ao amor dos pais pelos filhos, para debelar qualquer 
pretensão de revestir a generosidade de uma caridade mórbida porque intencionada em reproduzir a miséria para fortalecer o orgulho por sentimentos que apenas os bens materiais podem alimentar (TP, art. 82/ AT, XI, p. 388-389). Deve-se cuidar do outro, e nisso procurar lhe fazer o bem, sem almejar outra coisa senão o próprio fazer bem; o doar-se.

O controle das paixões é subordinado ao cuidado, mas o controle só ocorre quando os indivíduos deixam o conforto do si mesmo e reconhecem na prática do cuidado a única conduta que os torna protagonistas na condução das paixões. Ou seja, o cultivo do cuidado não é uma forma velada de egoísmo que subordina o cuidado do outro a uma reciprocidade que, quando não é materializada na forma da lei, é tacitamente aceita por uma sociedade de seres uniformemente racionais. É importante notar que o interesse do agente moral em controlar as paixões é subsidiário à dedicação ao cuidado do outro. $\mathrm{O}$ controle das paixões por meio do cuidado só funciona se o egoísmo moral for abandonado em nome da disposição genuína para o cuidado dos outros.

Portanto, o doar-se não deve ser confundido com uma abnegação total. Não se trata de um amor de missionário que é capaz de contemplar a dor como a redenção dos pecados. O cuidado tem como foco a relação no que ela pode constituir de atenção para com os outros, sobretudo, com os que são mais vulneráveis. Nesse sentido, o cuidado cartesiano é o cuidado maduro (reclamado por Carol Guilligan, 1982), visto que o agente moral só garante a sua felicidade quando se volta ao cuidado dos outros como uma disposição de solicitude para com seus problemas. Ou seja, cuidado e felicidade se harmonizam na ação dos generosos que são capazes de reconhecer que a realização dos interesses dos outros não exclui a sua própria felicidade, pelo contrário, a referida realização contribui para a felicidade de todos os agentes situados numa relação de cuidado. A felicidade é consequência do cuidado ou poderíamos dizer que é uma decorrência natural dos que cultivam a generosidade pelos outros na forma de um genuíno sentimento de atenção para com eles.

Nessa perspectiva, a competência moral não é a adesão a um conjunto de regras racionais que atravessam qualquer contexto e são válidas a priori, mas expressa uma adequação também racional da conduta humana à paixão que nos impele a sermos solícitos. A generosidade converte o apego às coisas que despertam orgulho e demais sentimentos, cujo centro de gravidade gira apenas em torno do eu e que nem sempre dependem dele, em autonomia da ação do agente moral, visto que, no cuidado irrestrito dos outros, o agente moral cumpre aquilo que está inteiramente ao seu alcance, aquilo que é exequível e que depende apenas dele. É na prática do cuidado que o bem moral se define. O cuidado do outro é o cuidado de si mesmo, desde que o objetivo seja a atenção para com 
a relação que instituímos com os outros com o propósito de torná-los felizes. Apenas a ação que se dispõe a cuidar dos outros é que carrega no seu seio a vocação moral para o controle - equilíbrio - das paixões. Contudo, resta saber o que leva os indivíduos a serem generosos. Sobre que patamar repousa a disposição afetiva para a generosidade?

\section{Vulnerabilidade e cuidado}

É possível conceder a um naturalista que a cooperação humana tem a sua raiz no instinto de sobrevivência. A generosidade pode ter sido uma ferramenta evolutiva importante por meio da qual os agentes morais se comprometiam a cuidar dos demais com a esperança de obter dividendos no futuro como a garantia de sua sobrevivência. Com efeito, é possível reconhecer a cooperação como marca essencial do nosso processo evolutivo sem deixar de defender que nosso compromisso moral muitas vezes se dirige para as ações que não decidem necessariamente a sobrevivência da espécie, mas apenas a vida de uma pessoa singular ou apenas o bem-estar dessa pessoa. Mesmo que hoje a morte de uma pessoa seja indiferente para a manutenção da espécie dificilmente estamos dispostos a deixar uma criança, que sequer conhecemos, na beira do precipício sem lhe prestar socorro. O que nos conduz a socorrer a criança passa, por entre outras coisas, pelo reconhecimento do seu estado de vulnerabilidade, sobretudo, em certas situações. Nesse sentido, acredito que a vulnerabilidade desencadeia uma disposição afetiva de cuidado, a generosidade, que nos conecta uns com os outros e faz que sejamos solícitos com aquela criança, do exemplo dado acima, para evitar que ela caia do precipício. Portanto, o reconhecimento da vulnerabilidade faz que cuidemos dos que não conseguem se movimentar no campo moral de forma correta ou que ainda não se constituem como agentes morais por não terem as suas capacidades cognitivas e afetivas plenamente desenvolvidas ou que estão sobre alguma condição especial.

As crianças, os idosos, os enfermos, os que não gozam de plenas condições afetivas e cognitivas são cuidados porque são reconhecidos como vulneráveis. Notadamente, todas as pessoas passam por essas condições de vulnerabilidade de sorte que ninguém deve se colocar como uma pessoa para qual não é necessária dispender cuidado porque ela seria completamente imune às falhas e poderia persistir na vida sem o auxílio de ninguém. É possível falar em termos de uma disposição sentimental que orienta a ação de vários agentes que estão no papel de cuidadores (pais, médicos, enfermeiras, bombeiros, etc.) a assumir a generosidade como protagonista dos sentimentos morais numa escala mais ampla em relação aos elos profissionais e familiares. Ainda que a 
generosidade se manifeste diferentemente de acordo com a relação entre cuidadores e cuidados, ela converge para um elo que é capaz de unir as pessoas para além de qualquer condição social e familiar, a amizade. É possível nutrir a amizade pelas mais diversas pessoas, mesmo por aqueles que nos ofendem.

Uma das principais origens de conflito e de sentimentos como a cólera repousa, segundo Descartes, na tendência que temos de revidar ofensas e torná-las uma barreira intransponível para uma relação afetiva entre os que impingem a ofensa e os que são ofendidos. No entanto, com o cultivo da amizade é possível superar as barreiras que separam as pessoas entre vítimas e algozes mediante o controle da cólera pelo fomento à tolerância. Nessa perspectiva, os que são generosos conseguem cumprir as exigências do cuidado e são capazes de se desviarem da cólera, sentimento que normalmente acompanha as pessoas que são vítimas de injúrias e ofensas, visto que, "apreciando muito pouco todas as coisas dependentes de outrem, nunca concedem tanta vantagem a seus inimigos, a ponto de reconhecer que são por eles ofendidos" (TP, art. 156/AT, XI, p. 401).

Os que são generosos são capazes de cultivar a amizade e, consequentemente, o cuidado com pessoas com fortes desvios e imperfeições ou, nas palavras de Descartes, "não há homem tão imperfeito que não se lhe possa dedicar amizade muito perfeita quando [...] se tem a alma verdadeiramente nobre e generosa" (TP, art. 83/AT, XI, p. 389-399). Assim, a tolerância que subjaz à argumentação cartesiana não é um princípio racional, mas é fruto da generosidade cujo alcance do toque pode acalentar com afago a mão que apedreja, pois pode converter ofensa em amizade por não imputar ao que ofende um valor maior para a ofensa que poderia tornar inviável a retratação. A disposição de estender os laços de amizade àqueles indivíduos cuja conduta é marcada por erros é a prova de que a generosidade pavimenta um terreno sobre o qual o ser humano caminha com compaixão suficiente para "quando ver a imperfeição dos outros homens" (TP, art. 187/AT, XI, p. 469-470) ouvir as suas queixas sem prejuízo e estar sensível a compreender os que vivem sob as variações de humor ${ }^{6}$. Portanto, a generosidade conduz as pessoas a serem mais tolerantes, mas não indiferentes às outras, pois ela cultiva a amizade no intuito de regenerar relações degradadas por sentimentos como cólera e inveja. A generosidade faz que a amizade, que implica cuidado, possa ser estendida para todos os seres humanos.

\footnotetext{
$6 \quad$ No Compendium Musicae, Descartes associa a força dos sentimentos despertados pela arte à sua capacidade de despertar a compaixão: "as elegias mesmas e as tragédias nos agradam tanto mais quanto mais excitam em nós compaixão e dor [...]" (AT, X, p. 97).
} 
A generosidade como cuidado se torna igualmente presente no texto cartesiano quando o leitor do Tratado das Paixões consegue reconhecer no amor dos pais pelos filhos a capacidade de estender o cuidado para além das fronteiras do círculo íntimo da família. Num artigo dedicado à amizade, Descartes abre o caminho, trilhado por reflexões posteriores de filósofos como Slote, cujo centro repousa numa ampliação do cuidado para as pessoas que eventualmente não conhecemos, mas que, no entanto, podemos guardar um comprometimento moral (SLOTE, 2007, p. 11), pois exige que se estendam os contornos da amizade, que limitam o cuidado a apenas um círculo restrito de pessoas, para todas as pessoas. Diferentemente de uma perspectiva do cuidado mais ligada a uma postura feminista (sobre esse ponto ver a diferença dentro de algumas das principais das posturas feminista em relação ao cuidado: KUHNEN, 2010), Descartes tende a não restringir o cuidado a uma relação de gênero ou a uma forma de relação específica, pois, segundo ele:

[...] que o amor de um pai por seus filhos é tão puro que nada deseja deles e não quer possui-los de outra maneira senão como o faz, nem estar unido a eles mais estreitamente do que já o está; mas, considerando-se como outros tantos ele próprio, procurar o bem deles como o seu próprio, ou mesmo com mais cuidado, porque, representado-se formar com eles um todo, do qual não é a melhor parte, prefere muitas vezes os interesses deles aos próprios e não teme perder-se para salvá-los. A afeição que as pessoas de honra sentem por seus amigos é dessa natureza, embora raramente seja tão perfeita [...] (TP, art. 82/AT, XI, p. 388-399 - ainda sobre o amor ver: carta a Chanut, 6 de junho de 1647 - AT, V).

Os sentimentos morais ou, mais precisamente o amor, é escalonado em sintonia com a proximidade entre os agentes morais - nada mais simétrico em relação à ética do cuidado em várias de susas matizes -, mas ele sempre se remete à obrigação moral de cuidar dos outros por meio do estabelecimento da prioridade dos seus sentimentos e desejos em relação aos interesses do próprio agente. Na própria definição de amor está contida a propriedade de cuidar como elemento central. Numa correspondência a Chanut, na qual Descartes discorre longamente sobre o amor, é possível recuperar o cuidado como o epicentro do sentimento que nos conecta aos outros de modo radical: "Car la nature de l'amour est de faire qu'on se considere avec l'objet aimé comme un tout dont on n'est que'une partie, et qu'on transfere tellement les soins qu'on a coutume d'avoir pour soi-même à la conservartion de ce tout" (carta a Chanut, $1^{\circ}$ de fevereiro de 1647 - AT, IV, p. 611). O cuidado intrínseco e constituinte das relações amorosas é a melhor maneira para que as pessoas se conectem por laços mais essenciais que as comprometem 
genuinamente com o outro pelo bem dele mesmo. O amor encerra uma forma de procurar o bem do outro como modo de estabelecer laços sociais mais sólidos porque inscritos em genuínas disposições afetivas de estar atento às demandas dos outros, sobretudo dos que são mais vulneráveis, como os filhos de pouca idade.

O epicentro da moral cartesiana consiste emeducar os sentimentos, dosar as paixões por meio da generosidade, para que o cuidado espontâneo e irreprodutível do ponto de vista de sua sentimentalidade dos pais para com os filhos possa se estender, na medida do possível, para o cuidado dos outros de modo geral. Assim, considerando que o epicentro da ética do cuidado repousa no cultivo do cuidado com os outros, em princípio com os mais próximos, mas que pode se estender para uma relação social mais ampla, a ética cartesiana guarda preocupações profundamente similares, quando não coincidentes, com a ética do cuidado.

Nesse sentido, ela compartilha com a ética do cuidado a convicção de que uma das principais formas de educar os sentimentos morais é avançar na direção contrária às paixões que transitam apenas no horizonte do interesse próprio. O orgulho deve ser diluído e a ambição que procura saciar os desejos do si mesmo deve ser conduzida, pela generosidade, a ser reconfigurada pela dedicação ao cuidado que pode corrigir não apenas nossos defeitos adquiridos ao longo da vida, mas também aqueles com os quais eventualmente nascemos. Como pontua Descartes no Tratado das Paixões:

[...] é certo, no entanto, que a boa formação muito serve para corrigir os defeitos do nascimento, e que se nos ocuparmos muitas vezes em considerar o que é o livre arbítrio, e quão grande são as vantagens advindas do fato de se ter uma firme resolução de usá-lo bem, assim como, de outro lado, quão inúteis e vãos são todos os cuidados que afligem os ambiciosos, podemos excitar em nós a paixão e em seguida adquirir a virtude da generosidade, sendo esta como que a chave de todas as outras virtudes e um remédio geral contra todos os desregramentos das paixões [...] (TP, art. 161/AT, XI, p. 453-454).

O quadro que Descartes desenha das paixões é claramente uma atitude pedagógica que visa a educar a alma e o próprio corpo para uma vida continuamente interpelada pela existência do outro. O Tratado das Paixões se impõe com uma obra em que está em jogo educar o uso das paixões por meio da promoção da generosidade que ensina a utilidade de cada paixão quando lhe confere uma medida certa. O remédio, ao qual a passagem se refere, não é a procura por uma pílula de aperfeiçoamento moral ou por algum elixir milagroso da medicina que nos tornaria impassíveis e anestesiados em face do efeito de qualquer paixão. $O$ 
remédio não é exógeno ao ser humano. Ele está dentro de nossas paixões. Ele revela uma capacidade constituinte de nossa espécie, a solicitude. A tese central do livro é que a melhor medicação para as paixões é a que fomenta seu controle pelo balanceamento dos seus efeitos. Convém recuperar na condição humana uma paixão que nos faça exercitar esse controle e que reclame a participação da razão no processo de avaliação e planejamento da vida com vistas à felicidade.

Deve-se notar ainda que a decisão de estabelecer regras para as paixões é uma decisão sentimental e não um decreto da razão imposto na forma de um dever moral desencarnado ou indiferente às emoções e cuja regra prescrita nos obriga a seguir de maneira incondicional um comportamento monolítico. Ou seja, a avaliação da moralidade de uma ação não é balizada por padrões instituídos a priori ou que poderiam transpassar qualquer contexto de ação porque se enraizariam em condições estruturais da racionalidade humana. Quando o leitor alcança nas suas correspondências as páginas em que o projeto de uma moral perfeita é sugerido, ele não encontrará nenhuma indicação de um conjunto de assertivas morais - imperativos - que poderiam o preparar para agir incondicionalmente frente a dilemas para os quais uma resposta moral é urgente. As várias páginas que compõem a obra cartesiana dedicada exclusivamente à moral não testemunham a presença forte de principialismo em termos morais. Por isso, a filosofia moral cartesiana não subordina o aperfeiçoamento moral à estrita observância a um catálogo de regras racionais cuja invariância está inscrita numa estrutura ideal que perpassa de maneira uniforme os diversos contextos morais.

O ponto é que a resistência de Descartes a enquadrar a sua moral numa rede de fórmulas prontas e aplicáveis a qualquer contexto de ação é subsidiária da sua decisão de entender a ação em função das paixões que a motivam ou que a causam. Por conseguinte, a travessia cartesiana no mar das paixões é para sintonizar os desejos humanos numa mesma frequência cujo epicentro repousa no outro ou, mais precisamente, na atitude de doar-se expressa no conceito de generosidade. Assim, ainda que Descartes não recorra ao termo empatia, muito comum nas abordagens da ética do cuidado, o cultivo da generosidade na forma do cuidado contínuo e permanente - lembro que a generosidade é um estado e não uma condição e, como tal, precisa ser alimentado - fornece subsídios suficientes para reconhecer que o cuidado só ocorre quando a disposição de cuidar já está presente na forma dos afetos. Ou seja, o cuidado não é uma operação da razão que decide, depois de um longo processo de introspecção, dedicar-se aos outros. O cuidado é uma prática que está presente nas relações amorosas de modo geral, como mostrei anteriormente. $\mathrm{O}$ exercício da generosidade é para estender o cuidado 
para além das fronteiras da família. Deve-se educar os sentimentos para que eles se ampliem, de sorte que o ser humano possa estender o cuidado para os que estão mais distantes.

Nesse ponto preciso, a preocupação cartesiana se coaduna com as reflexões de Virginia Held, que escreve: "A globalização das relações de cuidado ajudaria a permitir que as pessoas de diferentes estados e culturas vivessem em paz, respeitassem os direitos dos outros, cuidassem juntos dos seus próprios ambientes, e melhorassem a vida dos seus filhos" (HELD, 2006, p. 168). O epicentro da argumentação de Held consiste na articulação entre a vida moral das células constituintes da sociedade e as relações interculturais de diferentes grupos sociais. Ela tenta evitar que a ética do cuidado se refugie apenas nas relações de proximidade espacial. A proposta é cultivar o cuidado entre diferentes relações para que uma educação moral possa incorporar o cuidado como o elemento norteador de todas as relações humanas. Nesse sentido, a obrigação moral para os que estão distantes espacialmente não é negligenciada pela ética do cuidado em todos as suas matizes. Seu ponto é que não é necessário um princípio abstrato para me obrigar moralmente a cuidar daqueles que estão distantes, basta que a minha sensibilidade esteja suficientemente trabalhada para que ela possa se estender para outros seres humanos mais distantes. O cultivo do cuidado nas relações de proximidade não exclui o cuidado em escala mais ampla.

Descartes se posiciona no mesmo horizonte de argumentação que não restringe o cuidado apenas aos que nos cercam. Se é verdade que algumas matizes da ética do cuidado podem vetar uma ética universalista por lhe considerar uma variação do sexismo, é possível recuperar na obra de alguns autores uma preocupação em estender o cuidado para todas as relações humanas. Por exemplo, Descartes está entre aqueles que acredita que o amor pode ser uma ferramenta política de fortalecimento de laços sociais e não se restringir apenas ao âmbito da família. Por meio do amor é possível colocar interesses coletivos na frente de interesses estritamente individuais: "Toute de même quand um particulier se joint de volunté à son príncipe, ou à son pays, se son amour est parfaite, Il ne doit estimer que comme une fort petite partie du tout qu'il compose avec eux" (Carta a Chanut, $1^{\circ}$ de fevereiro de 1647 - AT, IV, p. 612).

O que gostaria de sublinhar aqui não é tanto o que Descartes compreende por um bom sistema político, mas apenas que o amor está presente nas relações sociais. O essencial nesta passagem é que o amor pode se estender para além das fronteiras do círculo familiar mais íntimo sobre a mesma prerrogativa de que é possível promover ações que não gravitem em torno do eixo do eu. Não é só possível como é da essência 
do cuidado e de algumas paixões (sentimentos morais) transpassar as condições emotivas que confluem para o egoísmo moral. Ou seja, não é apenas possível como é igualmente recomendável ter mais estima pelos outros do que por si mesmo. A extensão das relações amorosas que vinculam, na maior parte dos casos, pessoas de uma mesma família deve ser estendida, na medida do possível, para um contexto social mais amplo no intuito de tornar os laços sociais o espelho do respeito mútuo e, por conseguinte, da verdadeira virtude.

\section{Considerações finais}

Saber usar as paixões em favor da vida boa ou feliz é uma prerrogativa da razão;isso é inegável. Com efeito, procurei mostrar que só é possível saber usar bem as paixões e, com elas, o livre arbítrio, caso se reconheça que a direção para a qual as ações humanas que visam à felicidade devem se voltar, repousa na ação generosa. Nessa perspectiva, meu objetivo foi o de apresentar a generosidade como uma paixão que controla as demais paixões por meio do cultivo daquelas paixões que reconhecem no cuidado das pessoas o espelho da correção da atitude humana. A generosidade é a paixão que se converte em virtude porque, em função dela, é possível se livrar dos grilhões do próprio eu e realizar aquilo que reflete de modo pleno a nossa autonomia, a solicitude, o cuidado.

\section{Referências}

\section{Obras cartesianas}

DESCARTES, R. Euvres de Descartes. ADAM, C.; TANNERY, P. (Ed.). 2. ed. Paris: Vrin, 1986. $12 \mathrm{v}$.

. Descartes: Obra escolhida. Trad. J. Guinsburg e Bento Prado Júnior. Difusão Européia de Livro, 1962.

. As meditações de filosofia primeira. Trad. Fausto Castilho. Campinas: UNICAMPP, 2000.

\section{Outras fontes}

ANDRADE M. OLIVEIRA, É. O homem vazio: uma crítica ao utilitarismo. Trans/Form/ Ação, UNESP (Marília. Impresso), v. 26, 2013, p. 105-121.

. Le rôle de la méthode dans la constitution de la physique cartésienne. Paris: Sorbonne, 2006.

. A crítica de Nietzsche à moral kantiana: por uma moral mínima. Cadernos

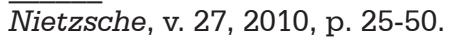

. La Génènse de la méthode cartésienne; la mathesis universalis et la rédactions de la Rèlge IV dans des Règles Pour la Dirction de L'Esprit. Dialogue - Canadian Philosophical Association, 2010. v. 49, p. 1-26. 
ANDRADE M. OLIVEIRA, É. Um imperativo sentimental: generosidade e altruísmo na ética cartesiana. In: CARVALHO, Marcelo; FIGUEIREDO, Vinícius (Org.). Filosofia do renascimento e moderna. 11. ed. Recife: UFPE/Anpof, 2014. v. 1, p. 153-171.

BENDEAU; HUMPHREYS. Emergence: Contemporary Readings in Philosophy and Science. USA, MIT, 2008.

CHAPPELL, V. Descartes's Compatibilism. In: Reason, will and sensation: studies Descartes's metaphysics. Ed. J. Cottngham (USA). Oxford: Clarendon Press, 1994.

COTTINGHAM, J. Cartesian reflections. Oxford: Oxford University Press, 2008

DALL'AGNOL, D. Uma análise conceitual do "cuidado" e as suas implicações. Florianópolis: UFSC, v. 9, n. 3, 2010, p. 29-36.

DELLA ROCCA, M. Judgment and Will. In: GRAUKROGER (Ed.). The Philosopher in Early Modern Europe: The Nature of a Contested Identity. Cambridge: Cambridge University Press, 2006.

DE SOARES, A. G. T. O filósofo e o autor. Campinas: Unicamp, 2008.

DONATELLI, M. C. O. F. Os Excerpta anatomica de Descartes: anotações sobre a fisiologia e a terapêutica. Scientiae Studia, USP, v. 6, 2008, p. 235-252.

FORLIN, E. A concepção cartesiana do sujeito: a alma e o animal racional. In: Educação e Filosofia, UFU: Edufu, v. 25, 2011.

GILLIGAN, C. In a different voice. USA: Havard University Press, 1982.

GILSON, E. La Liberté chez Descartes et la Théologie. Paris: Alcan, 1913.

GUEROULT, M. Descartes selon l'ordre de raisons. Paris: Aubier, 1966.

HELD, Virginia. The Ethics of Care. New York, NY: Oxford University Press, 2006.

KAMBOUCHNER, D. Descartes et la philosophie morale. Paris: Hermann, 2008.

KUHNEN, T. A ética do cuidado como alternativa à ética de princípios. In: Ethic@, Florianópolis: UFSC, v. 9, n. 3, 2010, p. 155-168.

LAUGIER, S.; MOLINIER, P.; PAPERMAN, P. Qu'est-ce que le care? Souci des autres, sensibilité, responsabilité. Paris: Éditions Payot et Rivages, 2009.

LANDIM, R. Evidência e verdade no sistema cartesiano. São Paulo: Loyla, 1992.

LEVY, L. 9 de fevereiro de 1645. Os novos rumos da concepção cartesiana da liberdade. Discurso, v. 31, 2000, p. 201-227.

NAAMAN-ZAUDERER, N. Descartes'deontological turn: reason, Will, and virtue in the last writings. Cambridge: Cambridge University Press, 2010.

NODDINGS, N. Cuidado: uma abordagem feminina à ética e à educação moral. São Leopoldo: Unisinos, 2003.

OLIVA, L. C. G. Apontamentos sobre a moral em Descartes. BioEticos, São Camilo, v. 2, n. 2, 2008, p. 163-176.

PINHEIROS, U. A terceira regra da "moral provisória" do Discurso do Método. O que nos faz pensar, Rio de Janeiro: PUC, n. 7, 1993, p. 7-21.

RENAULT, L. Generosidade e substancialidade da alma segundo Descartes. In: Educação e Filosofia, UFU: Edufu, v. 25, 2011.

RENAULT, L. Descartes et la félicité voluntaire. Paris: PUF, 2000. 
ROCHA, E. Animais, homens e sensação segundo Descartes. In: Kriterion, UFMG, v. 45, n. 110, 2004.

RODIW-LEWIS, G. Le Développement de la pensée de Descartes. Paris: Vrin, 1997.

SALES, B. A. Descartes: das paixões à moral. São Paulo: Loyola, 2013.

SHAPIRO, L. A ética de Descartes. In: BROUCHTON, J.; CARRIERO, J. (Org.). (2008). Descartes. Trad. Lia Levy e Ethe Rocha. Porto Alegre: Penso, 2011. p. 113-131.

SHIMITTER, A. Como fabricar um ser humano: paixão e explicação funcional em Descartes. In: BROUCHTON, J.; CARRIERO, J. (Org.). (2008). Descartes. Trad. Lia Levy e Ethe Rocha. Porto Alegre: Penso, 2011. p. 113-131.

SLOTE, M. The Ethics of Care and Empathy. New York, NY: Routledge, 2007.

SVENSSON, F. Happiness, Well-being, and their relation to virtue in Descartes'ethics. In: Theoria, n. 77, 2011, p. 238-266. doi:10/1111/j.1755-2567.2011.01101.x

TEIXEIRA, L. Ensaio sobre a moral de Descartes. São Paulo: Brasiliense, 1990.

TRONTO, J. Moral Boundaries: A Political Argument for an Ethic of Care. New York, NY: Routledge, 1994.

\section{Endereço postal:}

Universidade Federal de Pernambuco

Centro de Filosofia e Ciências Humanas - CFCH

Departamento de Filosofia

Av. da Arquitetura, $\mathrm{s} / \mathrm{n}^{\circ}, 15^{\circ}$ andar - Cidade Universitária

50740-550 Recife, PE, Brasil

Data de recebimento: 26/11/2013

Data de aceite: 13/04/2014 